MATEC Web of Conferences 11,03012 (2014)

DOI: 10.1051/matecconf/20141103012

(C) Owned by the authors, published by EDP Sciences, 2014

\title{
Concreting method that produce high modulus of elasticity
}

\author{
H.S. Abdelgader ${ }^{1}$ and A.S. Elbaden ${ }^{1}$ \\ ${ }^{1}$ University of Tripoli, Civil Engineering Department, Tripoli, Libya
}

\begin{abstract}
During the last decades, the concrete industry has been widely developing in many ways such as the methods of pouring concrete in order to achieve high quality concrete and low cost. Two-stage concrete is characterised by a higher proportion of coarse aggregate therefore the variation in aggregate content influences significantly its mechanical properties. The mechanical characteristics of the two-stage concrete (TSC) in failure conditions are dissimilar from the ordinary ones. Behaviour of TSC in compression has been well documented, but there are little published data on its behaviour in tension and modulus of elasticity. This paper presents the results of experimental testing of one type of coarse aggregate and three different mix proportions of grout. It was found that the modulus of elasticity and splitting tensile strength of two-stage concrete is equivalent or higher than that of conventional concrete at the same compressive strength.
\end{abstract}

\section{Introduction}

Two-stage concrete (TSC), also known as pre-placed aggregate concrete, derives its name from a unique placement method. Unlike conventional concrete, it is made by first placing coarse aggregate in the formwork and then injecting a cement grout to fill the voids between coarse aggregate particles [1-4]. Mechanical properties of TSC are thus influenced by the properties of the coarse aggregate [4], the properties of the grout [3,5], and the effectiveness of the grouting process $[6,7]$. When placed properly, TSC has beneficial properties such as low drying shrinkage, high bonding strength, high modulus of elasticity, and excellent durability [2]. The method of TSC has proved particularly useful in a number of applications like underwater construction, concrete and masonry repair, situations where placement by usual methods is extremely difficult, mass concrete where low heat of hydration is required, and tunnel and sluiceway plugs to contain water at high pressure where very low shrinkage is important $[1,2,8,9]$. It is also useful in the manufacture of high density concrete for atomic radiation shielding where steel and heavy metallic ores are used as aggregate [2]. TSC differs from conventional concrete not only in the method of placement but also in that it contains a higher proportion of coarse aggregate. TSC compressive strength is also different from conventional concrete because of the specific transmission of stresses that occur in TSC. The closepacked coarse aggregate exhibits contact areas in all directions, whereas in normal concrete the aggregate is usually smaller in size and rather dispersed. Thus the compressive stresses are mainly transmitted by the coarse aggregate $[5,10,11]$. The specific mechanism of stress distribution produces shear stresses and stress concentration in the contact areas. The modulus of elasticity is particularly important from the design point of view in plain or reinforced concrete, since it can describe the concrete mechanical behaviour. The elastic modulus and the failure characteristics of TSC differ from those of ordinary concrete. While the mechanical properties of TSC in compression have been well documented, there remains little published data on tensile strength and modulus of elasticity. The objective of this investigation was to study the strength of TSC in compression and tension and modulus of elasticity using different grout mixtures.

\section{Materials}

\subsection{Coarse Aggregate}

The coarse aggregate used in these experiments was sub angular basalt. A large sample was acquired, washed, and sieved to create the gradation with a maximum size of $50 \mathrm{~mm}$. The coarse aggregate had a bulk loose density $1430 \mathrm{~kg} / \mathrm{m} 3$, dry specific gravity of 2.687 , absorption of $0.34 \%$, and void ratio of $47 \%$. Because of its low absorption and high apparent specific gravity, this basalt is considered a high quality coarse aggregate.

\subsection{Cement Grout}

In this investigation, a simple mortar was used for the cement grout with admixtures (Superplasticizer) was used for all mixes and was added at the rate of $2 \%$ by weight of cement. The fine aggregate used in the manufacture of grout was produced from silica sand, which is subangular in shape with 100 percent passing a No. 8 sieve. The sand has an absorption of $1.05 \%$. The particle size distribution of sand is divided into three fractions: $2.0 / 1.0$ $\mathrm{mm}(13 \%), 1.0 / 0.25 \mathrm{~mm}(67 \%)$, and $0.25 / 0.0 \mathrm{~mm}$ 
(20\%),.The cement used throughout the experiments was ordinary (Type I) Portland cement. Water was used directly from the tap and was slightly colder $(21 \mathrm{C})$ than room temperature. The temperature in the lab when mixing and placing grout was near $27 \mathrm{C}$. For clarity, the cement grout will be referred to as mortar throughout this paper.

\section{Grout mixture proportioning and concrete specimen preparation}

The selection of water-cement-sand ratios is more critical in TSC because the amounts of sand and water control the pump-ability of grout, an essential requirement in the production of TSC [3]. Coarse aggregate was first placed in $150 \times 300 \mathrm{~mm}$ hard plastic cylindrical moulds. The void content of the preplaced aggregate was $47 \%$ and the bulk density $1430 \mathrm{~kg} / \mathrm{m} 3$. Five different proportions of water to cement $(0.42,0.45,0.50$ and 0.55$)$ were investigated with cement to sand ratios of $1 / 1.5,1 / 1$, and $1 / 0.8$. Grout preparation was accomplished by combining ingredients with an electric mixer for about three minutes to achieve the desired grout uniformity and consistency. Trials were made with grout to find the minimum waterto-cement $(\mathrm{w} / \mathrm{c})$ ratio at which the preplaced aggregate could be effectively grouted. A w/c ratio of 0.45 was found to be the minimum ratio suitable for grouting; it was not possible to penetrate all voids in the aggregate skeleton with a grout at a w/c ratio of 0.42 . The displacement of aggregate was less noticeable as the w/c ratio was increased; at a w/c ratio of 0.55 there was no displacement.

\section{Experimental program}

The experimental program consisted of a series of unconfined compression tests, split tensile tests and modulus of elasticity tests on cylinders prepared from different grout mixtures at ages of 28 days. To effectively compare the unconfined compressive strength to tensile strength, it was determined that all tests should be conducted using 150 × $300 \mathrm{~mm}$ cylindrical specimens prepared in the same manner. Excluding the specimens at a $\mathrm{w} / \mathrm{c}$ ratio of 0.42 , there were 81 concrete specimens tested. Three specimens from each one of the three grout mixtures were tested in unconfined compression, split tension and modulus of elasticity at 28 days. After one day of casting the concrete specimens were removed from the cylinders and covered with moist burlap for seven days and stored in the laboratory climate.

\section{Experimental test procedures}

Mortar cubes were prepared and tested in unconfined compression per ASTM C 942. Three cubes of each mortar were tested at 28 days using a universal hydraulic testing machine with $600 \mathrm{kN}$ capacity. Unconfined compression tests on two-stage concrete cylinders were tested in accordance with ASTM C 39. Three specimens of each concrete were tested at 28 days using a universal hydraulic testing machine with $2200 \mathrm{kN}$ capacity. Splitting tensile tests were also conducted on three specimens of each concrete at 28 days according to the procedures outlined in ASTM C 496. Splitting tensile tests were performed using the same machine as the mortar cubes. The splitting tensile strength is calculated using Equation 1 as follows:

$f_{S}=2 p / \pi l d$

Where: $f_{s}=$ Splitting tensile strength $[\mathrm{MPa}], \mathrm{p}=$ Maximum applied load $[\mathrm{KN}], \quad \mathrm{l}=$ Specimen length $[\mathrm{mm}]$, $\mathrm{d}=$ Specimen diameter $[\mathrm{mm}]$

\section{Investigation of strength of two-stage concrete}

\subsection{Compressive strength}

The unconfined compressive strength of TSC was measured at 28 days. In this way for each of the TSC type three cylinders were subjected to a compressive test after 28 days of curing. During the loading procedure, the vertical deformations were measured on three sides of the specimen with respect to axial force increment. On the basis of these results, stress and appropriate strain values were calculated. Some of the test results are presented in figure 1. At the same time 27 concrete cube samples (3 w/c ratios, $3 \mathrm{c} / \mathrm{s}$ ratios and one type of coarse aggregate) of $300 \times 300 \times 300 \mathrm{~mm}$ were tested for compressive strength. The results presented in Table 2 were calculated according to an algorithm, which was proposed earlier for designing of two-stage concrete [4]. Cylinders and the cubes have been cast and tested in the same conditions.

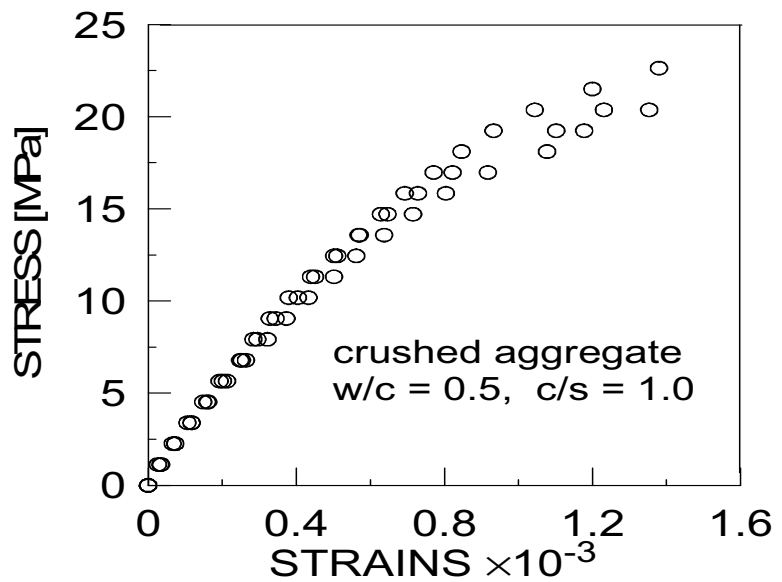

Fig. 1. Some results of compressive tests of two-stage concrete cylinder samples

figure 2 shows the mean and individual cylinder strengths of three specimens per $\mathrm{w} / \mathrm{c}$ ratio at ages of 28 days. It can be seen that mean compressive strengths of 31.9 is attainable at 28 days with a w/c ratio of 0.45 . figure 2 demonstrates a strength reduction as the w/c ratio increases. Although there is some variation in strength measured per $\mathrm{w} / \mathrm{c}$ ratio, the strength reduction is approximately linear Table 1. This observation is consistent with unconfined compressive strength measurements of TSC cube specimens $(300 \times 300 \times 300$ $\mathrm{mm}$ ), where Abdelgader [4] Table 2 determined the compressive strength of TSC at 28 days as:

$\bar{f}_{c}=62.08-71.00(w / c)+0.52(c / s)$ 
Equation 2 is illustrated in figure 2 for a c/s ratio of 1.0, and it can be seen that it under-predicts strength of the cylindrical specimens tested in this program. The predicted mean strength from Equation 2 is 87 to $93 \%$ of the measured mean strength. Decreasing the multiplicative factor on the $\mathrm{w} / \mathrm{c}$ ratio in Equation 2 to account for cylindrical specimens yields the following relationship:

$\bar{f}_{c}=62.08-68.00(w / c)+0.52(c / s)$

Only $\mathrm{c} / \mathrm{s}=1.0$ for specimens investigated herein. Further research is required to determine the suitability of Equation 3 for a range of $\mathrm{c} / \mathrm{s}$ ratios. Another significant finding from the compressive strength data was the somewhat limited rate of strength development. This can be explained, in part, because of the fact that no fly ash or other pozzolans were incorporated in the cement grout. The observations show that, although the mechanism of stress transfer is believed to be different from conventional concrete, the mortar strength is a controlling factor in the strength of two-stage concrete. Table 1 summarizes the mean and range of compressive strength of mortar and concrete at 28 days. Firstly, it can be seen that the range of measured compressive strengths at 28 days is sometimes high for both mortar and concrete. Secondly, the ratio of mean concrete-to-mortar strengths is reasonably consistent and calculates from 0.50 to 0.51 for all mixtures at 28 days. This observation suggests that the compressive strength of two-stage concrete can be conservatively estimated as one-half of its mortar strength. If this ratio can be substantiated with more mixtures and other sources of coarse aggregate, this simple rule-of-thumb can be adopted in the design of two-stage concrete.

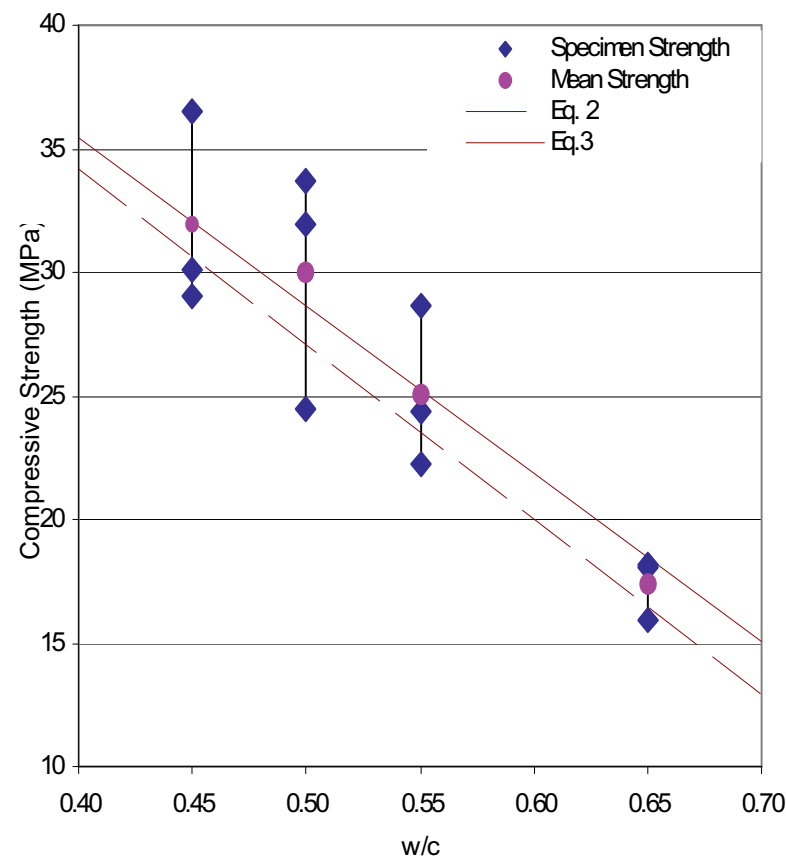

Fig. 2. Cylinder compressive strength vs. water-cement ratio at age of 28 days.
Table 1. Cylinder compressive strength of concrete and mortar at 28 days.

\begin{tabular}{|c|c|c|c|c|c|}
\hline \multirow{4}{*}{$\mathbf{W} / \mathbf{C}$} & \multirow{2}{*}{\multicolumn{2}{|c|}{$\begin{array}{c}\text { Concrete } \\
f_{\mathcal{C}}(28 \text { days })\end{array}$}} & \multicolumn{2}{|c|}{ Mortar } & \multirow{3}{*}{$\begin{array}{c}\text { concrete } \\
\text { : mortar } \\
\text { ratio }\end{array}$} \\
\hline & & & \multicolumn{2}{|c|}{$f_{c}{ }^{\prime}(28$ days $)$} & \\
\hline & \multicolumn{2}{|c|}{ (MPa) } & \multicolumn{2}{|c|}{$(\mathrm{MPa})$} & \\
\hline & Mean & Range & Mean & Range & \\
\hline 0.45 & 31.9 & 7.4 & 63.1 & 1.9 & 0.51 \\
\hline 0.5 & 30 & 9.2 & 60.3 & 15.2 & 0.5 \\
\hline 0.55 & 25.1 & 6.5 & 49.8 & 3 & 0.5 \\
\hline
\end{tabular}

Table 2. Cube compressive strength for various two-stage concrete types.

\begin{tabular}{|c|c|c|}
\hline $\begin{array}{c}\text { Water/Cement } \\
\text { ratio, }(\mathrm{W} / \mathrm{C})\end{array}$ & $\begin{array}{c}\text { Sand/Cement } \\
\text { ratio, }(\mathrm{S} / \mathrm{C})\end{array}$ & $\begin{array}{c}\text { Concrete } f c^{\prime}(28 \text { days }) \\
(\mathrm{MPa})\end{array}$ \\
\hline 0.45 & & 30.82 \\
0.45 & \multirow{3}{*}{$1 / 1.5$} & 27.82 \\
\cline { 3 - 3 } 0.45 & & 23.72 \\
\hline 0.5 & \multirow{3}{*}{$01-\mathrm{Jan}$} & 30.65 \\
\cline { 3 - 3 } 0.5 & & 27.1 \\
\hline 0.5 & & 23.55 \\
\hline 0.55 & \multirow{3}{*}{$1 / 0.8$} & 30.78 \\
\cline { 3 - 3 } 0.55 & & 27.23 \\
\hline 0.55 & & 23.68 \\
\hline
\end{tabular}

\subsection{Tensile strength}

The splitting tensile strength of TSC was also measured at 28 days. Table 3 shows the mean strengths of three specimens per w/c ratio at age of 28 days. The results indicate that a strength reduction as the $\mathrm{w} / \mathrm{c}$ ratio increases. However, there appears to be little difference in strength between specimens produced with a w/c ratio of 0.45 and those produced with a w/c ratio of 0.50 . This was also observed with the compressive strengths measured for the same grout mixtures. The actual values of tensile strength at $\mathrm{w} / \mathrm{c}$ ratios of 0.45 and 0.50 measured from 3.1 to $3.3 \mathrm{MPa}$, which indicate satisfactory results, especially when one considers the minimum cost of concreting and that no vibration tools are used. Furthermore, excellent results can be expected even when using a high $\mathrm{w} / \mathrm{c}$ ratio of 0.55 , where the mean tensile strength is nearly $2.73 \mathrm{MPa}$. Test observations show that failure in splitting tension was restricted principally to the line of split and occurs through the mortar and coarse aggregate. Visual assessments of the failed specimens suggest that the percentage of failed aggregate increased in concrete with higher mortar strength (lower w/c ratio).

Table 3. Mean tensile strength of concrete at 28 days

\begin{tabular}{|c|c|}
\hline W/C & $\begin{array}{c}28 \text { days tensile strength } \\
(\mathrm{MPa})\end{array}$ \\
\hline 0.45 & 3.21 \\
\hline 0.5 & 3.11 \\
\hline 0.55 & 2.73 \\
\hline
\end{tabular}




\subsection{Compressive-tensile strength relationship}

The results of this investigation show that the splitting tensile strength of TSC can be approximated well by the ACI equation for conventional concrete, as shown in figure 3. For conventional concrete, the predictive equation is given by:

$$
f_{s}^{\prime}=0.56 \sqrt{f_{c}^{\prime}}
$$

where $f_{c}^{\prime}$ and $f_{s}^{\prime}$ are in units of MPa. In this investigation, the splitting tensile strengths can be estimated as:

$$
f_{s}^{\prime}=(0.55-0.58) \sqrt{f_{c}^{\prime}}
$$

which conforms closely to the ACI equation (Equation 4). Equation 4 is also valid for estimating 90-day splitting tensile strengths based on 90-day compressive strengths, as the data in figure 3 suggest. In this investigation, the factor in Equation 4 ranges from 0.52 to 0.56 for 90 -day strengths. figure 3 includes compressive and tensile strength results from a concurrent investigation by Abdelgader [12]. In that investigation, 150 × $300 \mathrm{~mm}$ concrete cylinders were produced with a similar mortar mixture (w/c ratios of $0.45,0.50,0.55$ and 0.60 at a $\mathrm{c} / \mathrm{s}$ ratio of 1.0). The coarse aggregate source was a crushed dolomitic limestone from Rage'at, located $45 \mathrm{~km}$ south of Tripoli, Libya. Particles were subangular in shape and the gradation was uniform, with almost all particles passing a $50 \mathrm{~mm}$ sieve and retained on a $37.5 \mathrm{~mm}$ sieve. The physical characteristics of that limestone and this granite are quite similar, but the results show a higher splitting tensile strength for two-stage concrete produced with limestone. The splitting tensile strengths can be estimated as

$$
f_{s}^{\prime}=(0.63-0.68) \sqrt{f_{c}^{\prime}}
$$

The data from both studies show that the tensile strength of TSC is at least as high as that of conventional concrete, and in fact it can be higher depending on the selection and properties of the coarse aggregate. No causes were apparent for the relatively higher tensile strength in twostage concrete. However, the greater mechanical interlocking among particles in two-stage concrete could be responsible for the higher tensile strength since factors like aggregate gradation are different from conventional concrete. These observations warrant a much deeper investigation into the influence of coarse aggregate properties on two-stage concrete behavior in tension.

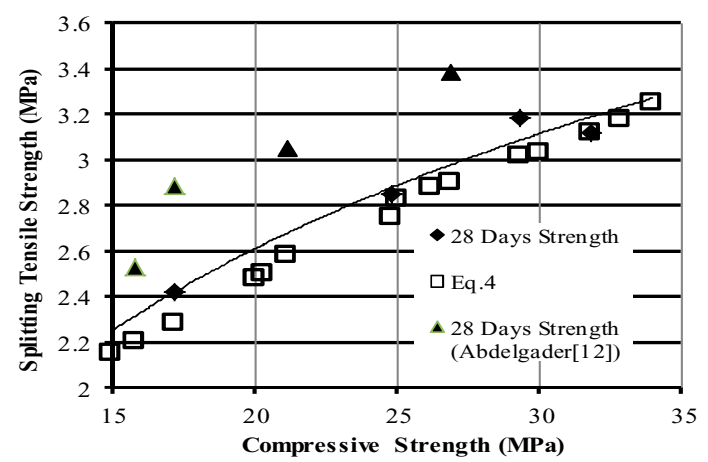

Fig. 3. Mean splitting tensile strength vs. mean unconfined compreeeive strength.

\subsection{Stress-Strain relations}

The obtained results are statistically analysed to estimate equations for the compressive strain-stress relations of various two-stage concrete types. The statistical analysis is performed by use of the MINITAB program [13]. The Minitab Regress Package fits an equation to the experimental data by the least square method. The calculation can be divided into the following steps: assumption of the mathematical relation, estimation of the equation coefficients, testing of the assumed equation and choice of the best model. The statistical analysis of the TSC test data is performed in two successive phases. First, equations for stress-strain relations for type of coarse aggregate and different grout proportions are estimated. In this step the data consist of $27\left(\begin{array}{ll}3 & 9\end{array}\right)$ stressstrain sets of experimental results obtained from cylinder compressive tests. After various trials the following simple relation for all concrete types is:

$\hat{\sigma}=a \varepsilon_{1}^{3}+b \varepsilon_{1}^{2}+c \varepsilon_{1} \quad[\mathrm{MPa}]$

In the above formulae $\hat{\sigma}$ stands for the estimated concrete stresses, and $\varepsilon_{1}=\varepsilon \times 10^{3}$, where $\varepsilon$ denotes the concrete strain. The constants $a, b$, and $c$ in Eq. (7) for each concrete type are statistically obtained. In Table 4 some results ( 6 out of 18 test data sets) for $\mathrm{c} / \mathrm{s}=1 / 1.5$ and various $\mathrm{w} / \mathrm{c}$ ratios are presented. Equation (7) gives reliable results in the following range of strains:

$0 \leq \varepsilon \leq 0.001$

Table 4. Constants a, b, c of equation (7) for coarse aggregate type and $\mathrm{c} / \mathrm{s}=1 / 1.15$

\begin{tabular}{|c|c|c|c|c|c|}
\hline $\begin{array}{c}\text { Aggregate } \\
\text { type }\end{array}$ & w/c & $\mathrm{a}$ & $\mathrm{b}$ & $\mathrm{c}$ & $\begin{array}{c}\text { Correlation } \\
\text { coefficient }\end{array}$ \\
\hline & 0.45 & 9.15 & -27 & 34.9 & 0.9846 \\
& 0.5 & 0.08 & -17 & 33.3 & 0.9931 \\
& 0.55 & 5.84 & -23 & 36.2 & 0.9983 \\
\hline
\end{tabular}

Typical statistically obtained stress-strain curves for twostage concrete in different grout proportions and type of coarse aggregate are presented in figure 4.

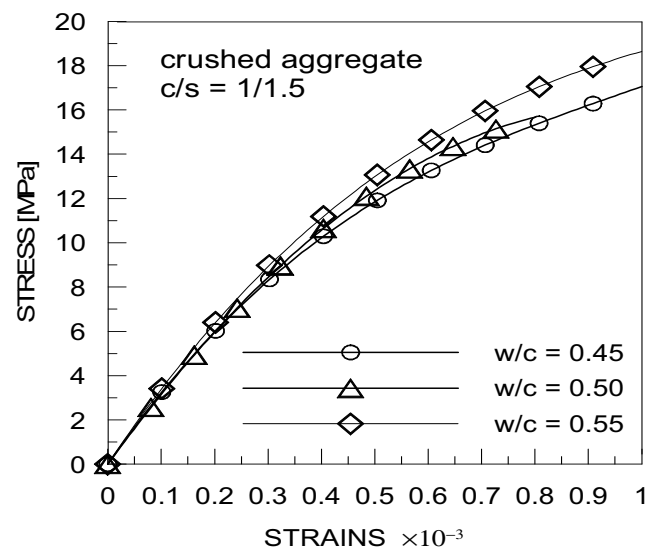

Fig. 4. Stress-strain relations for various TSC (Eq.7). 
In the second step the statistical analysis is used to obtain the two-stage concrete stress-strain relations as function of water-cement $(\omega=\mathrm{w} / \mathrm{c})$ and cement-sand ( $\varsigma=\mathrm{c} / \mathrm{s}$ ) ratios. After a complex analysis the functions $a=a(\omega, \varsigma), b=b(\omega, \varsigma)$ and $c=c(\omega, \varsigma)$ in Eq. (7) are assumed as follows:

for crushed aggregate:

$$
\begin{aligned}
& a(\omega, \varsigma)=14.9-17.1 \omega+1.89 \varsigma, \\
& b(\omega, \varsigma)=-28.7+1.0 \omega+9.63 \varsigma, \\
& c(\omega, \varsigma)=37.9+4.0 \omega-7.82 \varsigma,
\end{aligned}
$$

Some estimation results for concrete stresses according to Eq. (7) by use of functions (9) is presented in Table 5. The values of the correlation coefficient reveal that using the function $a(\omega, \varsigma), b(\omega, \varsigma)$, and $c(\omega, \varsigma)$ the test results and their estimators are more dispersed (compare Table 4 and 5).

Table 5. Correlation constants calculated according toeq.(9)

\begin{tabular}{|l|l|l|l|l|l|}
\hline $\begin{array}{c}\text { Aggregate } \\
\text { type }\end{array}$ & $\mathrm{w} / \mathrm{c}$ & $a(\omega, \varsigma)$ & $b(\omega, \varsigma)$ & $c(\omega, \varsigma)$ & $\begin{array}{l}\text { Correlation } \\
\text { coefficient }\end{array}$ \\
\hline \multirow{4}{*}{ Crushed } & 0.45 & 8.47 & $\begin{array}{l}-21.8 \\
3\end{array}$ & 34.49 & 0.8083 \\
\cline { 2 - 6 } & 0.5 & 7.61 & $\begin{array}{l}-21.7 \\
8\end{array}$ & 34.69 & 0.8143 \\
\cline { 2 - 6 } & 0.55 & 6.76 & $\begin{array}{l}-21.7 \\
3\end{array}$ & 34.89 & 0.7357 \\
\hline
\end{tabular}

The test observations and the statistical analysis have proved that the linear part of the stress-strain curve in two-stage concrete may reach $85 \%$ of the ultimate cylinder strength (see Fig. 4). This may result from a very good contact between the aggregate particles. In consequence the applied load is distributed mainly by the stones. During the laboratory tests it was observed that the skeleton of the two-stage concrete carried the load until the whole specimen collapsed. It was the reason why the failure of the two-stage concrete was not sudden and explosive but rather gradual. The failure specimen showed extensive lateral expansion in the form of bulging. Thus the specific stress-strain characteristics of the two-stage concrete can be explained by a dominant influence of the rigid stone skeleton. It should be pointed out that the stress-strain relations of traditional concrete result from transfer of stress through the mortaraggregate uniform matrix. In the two-stage concrete there are no such uniform relations because the mechanical properties of two-stage concrete are mainly determined by the characteristics of the stone aggregate. Therefore, the subsequent fracture of the two-stage concrete takes place through the stone aggregate particles [10]. In the TSC the compressive stresses in the aggregate and in the grout cannot be equal. The compressive stress is influenced by the shear stresses occurring not only in the vertical section but also in the horizontal contact surfaces.
The produced shear stress caused the tearing off of the aggregate grains from grout. It was also observed that some microcracking or interfacial cracks were randomly distributed even before the specimens were subjected to load testing. It seems that these cracks were caused by bleeding, settlements of grout, or by shrinkage stresses induced by the drying process. The cracks formed within the grout may be considered to be isolated or discontinuous.

\subsection{Modulus of elasticity}

The experimental data analysis and the statistically obtained stress-strain relations allow for formulating the relationship between the modulus of elasticity and the compressive strength of the two-stage concrete ( ). The compressive strength (Table 2) is calculated according to the algorithm for designing the two-stage concrete proposed by Abdelgader, [4]:

$\bar{f}_{c}=\beta_{0}+\beta_{1} \cdot \bar{f}_{g}^{\beta_{2}}$

Where: $\bar{f}_{g}$ stands for compressive strength of grout [MPa], $\beta_{0}, \beta_{1}$ and $\beta_{2}$ are constants obtained from regression analysis and are given in Table 6 p. 335 [4]. The modulus of elasticity of the TSC is mainly affected by the physical properties of the coarse aggregate. The influence of the content of grout in the concrete is rather meaningless. It has been observed that the same factors that affect the compressive strength also alter the elastic modulus of the TSC. The elastic modulus is obtained from the analysis of the stress-strain curves for each type of stone aggregate and the mix proportions. The initial tangent modulus of elasticity of the TSC is found with reference to the tangent line drawn to the stress-strain curve at the starting point (compare some examples presented in figure 5).

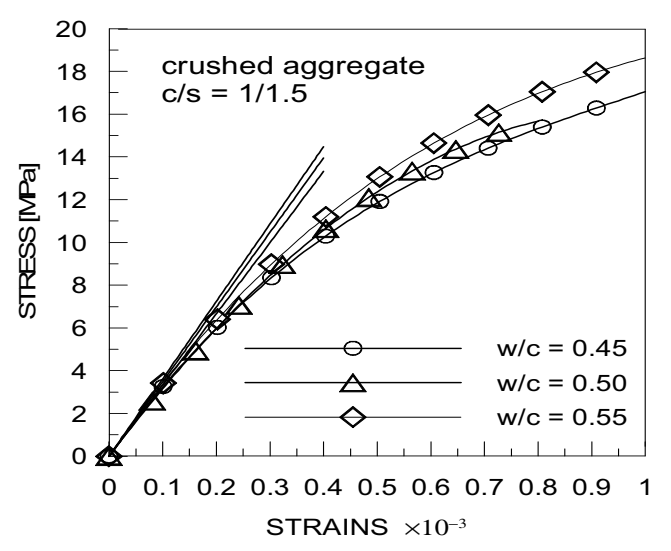

Fig. 5. Graphical presentation of modulus of elasticity of TSC.

The modulus of elasticity of two-stage concrete $E_{t s c}\left(\varepsilon_{1}\right)$, determined as a function of strains $\mathcal{E}\left(\varepsilon_{1}=\varepsilon \cdot 10^{3}\right)$, can be calculated in GPafrom Equation (11) as follows:

$E_{t s c}\left(\varepsilon_{1}\right)=\frac{d \hat{\sigma}}{d \varepsilon_{1}}=3 \cdot a(\omega, \varsigma) \cdot \varepsilon_{1}^{2}-2 \cdot b(\omega, \varsigma) \cdot \varepsilon_{1}+c(\omega, \varsigma)$ 
Assuming that $\varepsilon_{1}=0$ the concrete modulus $E_{t s c}$ is estimated as:

$$
E_{t s c}=c(\omega, \varsigma)
$$

(12)

Equation (12) indicates that function $c(\omega, \varsigma)$, calculated according to Eq. 9, determines the elastic modulus of the two-stage concrete. It should be mentioned that the values of the elastic modulus obtained for $30 \%$ of the cylinder ultimate strength are almost the same. In this way the initial linear feature of the strainstress relation of the TSC has been proved. It is possible to elaborate an alternative version of the elastic modulus formulae. Making use of the regression analysis of the experimental data expressions describing the relationship between the elastic modulus and the compressive strength of the TSC the following assumption can be made:

$\mathrm{E}_{\mathrm{tsc}}=33.9-0.049(\mathrm{GPa})$

Where $\bar{f}_{\mathrm{c}}$ is the cube compressive strengths (Eq. 10 and Table 2). The limit value of the cube compressive strengths $\bar{f}_{\mathrm{c}}$ in equation (13) is:

$23 \mathrm{MPa} \leq \bar{f}_{\mathrm{c}} \leq 32 \mathrm{MPa}$

Equation (13) relation is graphically presented in figure 6 . It should be noticed that the obtained values of the modulus of elasticity are rather scattered figure 6 . This can be explained by the random allocation of coarse aggregate in the forms. Nevertheless, Eq. (13) allows for the approximate determination of the modulus of

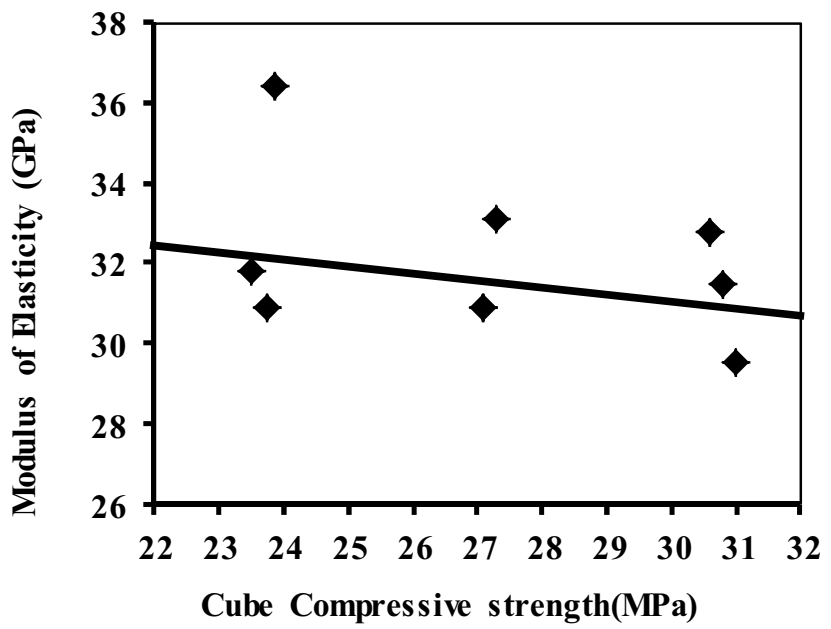

elasticity for the examined crushed aggregate. It should be pointed out that the obtained results deviate at most \pm $10 \%$ from the calculated mean values figure 6.

Fig. 6. Relation between modulus of elasticity and compressive strength of TSC.

\section{Conclusions}

The following conclusions can be drawn from this study:

1. A grout mixture with a water-to-cement $(\mathrm{w} / \mathrm{c})$ ratio of 0.45 to 0.55 and a cement-to-sand $(\mathrm{c} / \mathrm{s})$ ratio of 1.0/1.5, 1.0/1.0 and 1.0/0.8 optimizes compressive and tensile strength of TSC. Mortar mixed with a w/c ratio below 0.42 is too viscous and does not fully penetrate the voids between coarse aggregate particles, thus creating a honeycombing effect in the hardened concrete.

2. Compressive strength of TSC cylinders can be conservatively estimated as $50 \%$ of the mortar cube strength.

3. The splitting tensile strength of TSC was found to be similar to that predicted by the ACI equation for splitting tensile strength of conventional concrete. In some cases, the measured tensile strength of TSC is in fact higher than that predicted by the ACI equation.

4. The stress-strain relationships for different grout mixes (water/cement ratios and cement/sand ratios) do not show a big difference. The initial stress-strain curves can be estimated by linear relations. This may result from the stresses distributed mainly by the particles of stone aggregate (skeleton of stones). The specific way of stress transmission may also contribute to the initiation and propagation of cracks.

5. The modulus of elasticity as a function of compressive strength of the TSC is elaborated. The modulus values for specific type of aggregate is described by linear constant functions. The obtained equations allow engineers to design the TSC according to the algorithm presented in [4].

\section{References}

1. King, J.C., Handbook of Heavy Construction Concrete by Intrusion Grouting, McGraw-Hill, New York, pp.211-234 (1959)

2. ACI Committee 304, Guide for The Use of Preplaced Aggregate Concrete for Structural and Mass Concrete Applications, ACI 304.1 R-92., pp.21-24 (1997)

3. Abdelgader, H.S., Effect of Quantity of Sand on The Compressive Strength of Two-Stage Concrete, Magazine of Concrete Research, 48, pp. 353-360 (1996)

4. Abdelgader, H.S., How to design Concrete Produced by a Two-Stage Concreting Method, Cement and Concrete Research, 3 29, pp. 331-337 (1999).

5. Abdelgader, H.S. and Górski, J, Influence of Grout Proportions on Modulus of Elasticity of Two-Stage Concrete," Magazine of Concrete Research, 4, pp. 251255 (2002).

6. Iwasaki, N., Predictions of Grouting Process in Pre-packed Concrete by Green's Function, Proceeding of Japanese Society of Civil Engineering, pp. 41-50 (1985).

7. Swaddiwudhipong, Zhang, S., J. and Lee, S.L., Viscometric Characterisation of Cement Grout for Prediction of Pre-packed Concrete Construction, Magazine of Concrete Research, 5, pp. 365-376 (2002). 
8. King, J.C. and Wilson, A.L., If it's still Standing, It Can be Repaired, Journal of Concrete Construction, 3, pp. 643-650 (1988)

9. Colle, E.R., Preplaced Aggregate Concrete Repairs 63-Year-Old Railroad Bridge, Concr. Rep. Dig., The Aberdeen Group.(1992).

10. Abdul Awad, A.S.M., Failure Mechanism of Prepacked Concrete, ASCE J. Struct. Eng., 3, pp. 727-732 (1988).

11. Abdelgader, H.S., and Górski, J., Stress-Strain Relations and Modulus of Elasticity of Two-Stage Concrete, ASCE J. Mat. Civ. Eng., 4, pp. 251-255 (2003)

12. Abdelgader, H.S., and Elgalhud A. A., Effect of Grout Proportion on Strength of Two-Stage Concrete, Structural Concrete, 3, pp.163-170 (2008).

13. SCHAEFER, R.L., ANDERSON, R.B., The students edition of MINITAB statistical software adapted for education. Addison-Weslley Publishing Company, Inc. (1989). 